the Total Environment

Elsevier Editorial System(tm) for Science of Manuscript Draft

Manuscript Number: STOTEN-D-17-07833R1

Title: GRAVEL BEACHES NOURISHMENT: MODELLING THE EQUILIBRIUM BEACH PROFILE

Article Type: Research Paper

Keywords: Cross-shore profile; gravel beaches; Posidonia oceanica; sediment samples; wave characteristics; numerical models

Corresponding Author: Dr. Luis Aragones Pomares, Assistant Professor

Corresponding Author's Institution: University of Alicante

First Author: Isabel López

Order of Authors: Isabel López; Luis Aragones Pomares, Yolanda Villacampa; Francisco J Navarro-González

Abstract: The erosion of the world's coasts and the shortage of sand to mitigate beach erosion is leading to the increasingly common use of gravel for coastal protection and beach nourishment. Therefore, in order to determine the amount of gravel required for such actions, it is important to know perfectly the equilibrium profile of gravel beaches. However, at present, this profile is obtained from formulas obtained mainly after channel tests, and therefore most of them do not adapt to the real profiles formed by gravel beaches in nature. In this article, 31 variables related to sedimentology, waves, morphology and marine vegetation present on the beaches are studied to determine which are the most influential in the profile. From the study carried out, it is obtained that these variables are the steepness and probability of occurrence of the wave perpendicular to the coast, the profile starting slope (between MWL and $-2 \mathrm{~m}$ ), the energy reduction coefficient due to Posidonia oceanica as well as the width of the meadow. Using these variables, different numerical models were generated to predict accurately the gravel beach profile, which will lead to a saving in the volume of material used in the order of $1300 \mathrm{~m} 3 / \mathrm{ml}$ of beach with respect to current formulations, and a greater certainty that the beach nourishment carried out will have the desired effect. 


\title{
GRAVEL BEACHES NOURISHMENT: MODELLING THE EQUILIBRIUM BEACH PROFILE
}

\author{
I. López ${ }^{\left(a^{*}\right)}$, L. Aragonés ${ }^{(a)}$, Y. Villacampa $^{(b)}$, F.J. Navarro-González ${ }^{(b)}$
}

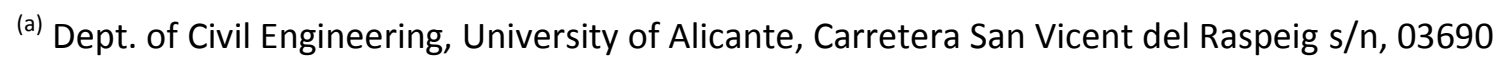
Alicante, Spain.

(b) Dept. of Applied Mathematics, University of Alicante, Carretera San Vicent del Raspeig s/n, 03690 Alicante, Spain.

${ }^{(*)}$ Corresponding Author. Isabel López. E-mail: isalopu.il@gmail.com

\section{ABSTRACT}

The erosion of the world's coasts and the shortage of sand to mitigate beach erosion is leading to the increasingly common use of gravel for coastal protection and beach nourishment. Therefore, in order to determine the amount of gravel required for such actions, it is important to know perfectly the equilibrium profile of gravel beaches. However, at present, this profile is obtained from formulas obtained mainly after channel tests, and therefore most of them do not adapt to the real profiles formed by gravel beaches in nature. In this article, 31 variables related to sedimentology, waves, morphology and marine vegetation present on the beaches are studied to determine which are the most influential in the profile. From the study carried out, it is obtained that these variables are the steepness and probability of occurrence of the wave perpendicular to the coast, the profile starting slope (between MWL and $-2 \mathrm{~m}$ ), the energy reduction coefficient due to Posidonia oceanica as well as the width of the meadow. Using these variables, different numerical models were generated to predict accurately the gravel beach profile, which will lead to a saving in the volume of material used in the order of 1300 $\mathrm{m}^{3} / \mathrm{ml}$ of beach with respect to current formulations, and a greater certainty that the beach nourishment carried out will have the desired effect.

Keywords: Cross-shore profile; gravel beaches; Posidonia oceanica; sediment samples; wave characteristics; numerical models

\section{INTRODUCTION}

Gravel beaches are an important form of coastal natural defence (Lopez de San Roman Blanco, 2003; Poate et al., 2013), due to the characteristics offered by this type of sediment, such as hydraulic roughness and permeability (Van Wellen et al., 2000), or their natural ability to dissipate large amounts of waves energy (e.g., Aminti et al. (2003); Johnson (1987)). As a result, beach nourishment with coarse-grained material or a mixture of sand and gravel is becoming more and more frequent (Mason et al., 2007). It is important to highlight the economic implications that the choice of the equilibrium profile has on these beach nourishment. Since it has been observed that bad designs can cause the rupture of the berm and the consequent overflowing of waves during extreme events, producing high social costs 
in the form of damage to coastal properties and infrastructure, flooding of the hinterland and loss of human life (McCall et al., 2015), hence the importance of good design.

In order to successfully predict the dynamic behaviour of gravel beaches, it is necessary to identify and represent the equilibrium of key processes that control sediment dynamics in the swash zone (Puleo et al., 2000). It is important to understand that the balance of the processes governing this behaviour is different from that of sandy beaches, where, for example, infiltration is negligible (Baldock and Holmes, 1997). In general, during surf conditions, on gravel beaches, sediment is carried upwards where it spreads and deposits in the form of a berm at the top of the beach; this also leads to a steeper slope of the beach face (Austin, 2005; Carter and Orford, 1993; Jamal et al., 2014). This foreshore accretion and increase in beach face slope are against the force of gravity, which requires either the uprush and backwash velocities, or the amounts of sediment transported between uprush and backwash, to be asymmetric (Aagaard and Hughes, 2006).

The complex processes associated with gravel beaches make it difficult to predict accurately morphological changes. Various approaches to variable complexity modelling have been reported, which were generally adopted to describe model families from 1 to 3-D. That is, models that cover a single parameter or element (winds (Benetazzo et al., 2012); hydrodynamic processes (Perlin and Kit, 1999; Saengsupavanich et al., 2008); sediment transport (Fredsoe et al., 1985)); or models that merge several numerical models into one (Bonaldo et al., 2015). These include parametric models (e.g., Powell (1990)) and processbased models (e.g., Clarke et al. (2004); Jamal et al. (2014); Masselink and Li (2001); PedrozoAcuña et al. (2006)). Thus, authors like Powell (1990), Van der Meer (1988) or López et al. (2016), suggest a power function for the equilibrium profile of gravel beaches, specifically for the area between mean water level (MWL) and step (Equation 1).

$$
h=A x^{B}
$$

Regarding the value of parameter A, many authors have also proposed formulations to obtain it on sandy beaches, such as Dean (1977), Moore (1982), Bodge (1992) and Pilkey et al. (1993), which they consider to be exclusively dependent on the median sediment size $\left(D_{50}\right)$. However, there are authors such as Stockberger and Wood (1990) that doubt the dependence between profile and sediment size. In turn, Boon and Green (1988) states that in addition to sediment size, parameter $A$ must be influenced by wave energy. More recent authors such as Turker and Kabdasli (2006) developed a formulation with terms increasingly complex and difficult for the coastal engineer to handle, introducing the effect of energy dissipation by breaking waves in their formulation.

At present, the only empirical or parametric models available for obtaining parameters $A$ and $B$ for coarse-grained profiles are Powell's (1990) and Van der Meer's (1988), based on extensive channel-scale testing (small scale with anthracite for Powell's profile and large and small scale with gravel for Van der Meer's). Van der Meer (1988) proposed a value of 0.83 for parameter B and Equation 2 for parameter $\mathrm{A}$.

where:

$$
\mathrm{A}=\frac{\mathrm{h}_{\mathrm{s}}}{\left(-\mathrm{l}_{\mathrm{s}}\right)^{0.83}}
$$




$$
\mathrm{h}_{\mathrm{s}}=0.22 \cdot\left(\frac{\mathrm{H}_{\mathrm{s}}}{\mathrm{L}_{\mathrm{o}}}\right)^{-0.3} \cdot \mathrm{H}_{\mathrm{s}} \cdot \mathrm{N}^{0.07}
$$

$$
\mathrm{l}_{\mathrm{s}}=\left(\frac{\mathrm{H}_{\mathrm{o}} \cdot \mathrm{T}_{\mathrm{o}}-180}{3.8}\right)^{1 / 1.3} \cdot \mathrm{D}_{\mathrm{n} 50} \cdot \mathrm{N}^{0.07}
$$

and $N$ is the number of storm waves, $D_{n 50}$ is the nominal diameter defined as $\left(W_{50} / \rho_{a}\right)^{1 / 3} \cdot W_{50}$ is the value of $50 \%$ of the mass in the distribution curve and $\rho_{a}$ is the density of the material.

Powell (1990) proposed two equations for parameters B (equation 5) and A (equation 6).

$$
\mathrm{B}=\mathrm{n}_{2}=0.84-16.49 \cdot\left(\frac{\mathrm{H}_{\mathrm{s}}}{\mathrm{L}_{\mathrm{m}}}\right)+290.16 \cdot\left(\frac{\mathrm{H}_{\mathrm{s}}}{\mathrm{L}_{\mathrm{m}}}\right)^{2}
$$

where

$$
A=\frac{h_{t}}{\left(P_{t}\right)^{n_{2}}}
$$

These formulations mainly depend on the median sediment size $\left(D_{50}\right)$, as well as significant wave height $\left(H_{s}\right)$, mean wavelength $\left(L_{m}\right)$ and mean period $\left(T_{m}\right)$.

On the other hand, uncertainty in the data collection of the parameters that are considered as inputs must be taken into account, e.g. where sediment samples should be taken to determine the median grain size $\left(D_{50}\right)$ or the type of wave to be used (deep water, shallow water or breaking wave) or the direction of the wave. An inappropriate choice of these variables implies uncertainties in the definition of parameters $A$ and $B$ and large errors in the final shape of the designed beach.

Therefore, the objectives of this study are: i) to analyse the variables that may affect the equilibrium profile of gravel beaches. ii) Develop a methodology that allows us to select the most important variables. iii) Define and test a model that allows us to obtain parameters $A$ and B proposed by López et al. (2016) for the profile between the mean water level and the Posidonia oceanica meadow, which were obtained through field measurements.

\section{STUDY AREA}

The study area includes 51 gravel beaches located in the provinces of Alicante and Murcia (Spain). It is a micro-tidal zone where the astronomical tides oscillate between 20 and $30 \mathrm{~cm}$, and together with the meteorological tides can reach up to $75 \mathrm{~cm}$ (Ecolevante, 2006; EcoMAG, 2009).

In the province of Alicante, we find 34 gravel beaches, which are located mainly in the northern part of the province (Figure 1a). It is the most mountainous area of the province where the coastal landscape is formed mainly by rocky cliffs and small coves. From north to south, the terrain passes from large limestone cliffs to small gravel and silt cliffs. 
In the province of Murcia, the 17 gravel beaches are located in the southwestern area (Figure 1b), where we find mainly cliffs with small beaches. In this area, along with the province of Alicante, there are important extensions of Posidonia oceanica meadows.

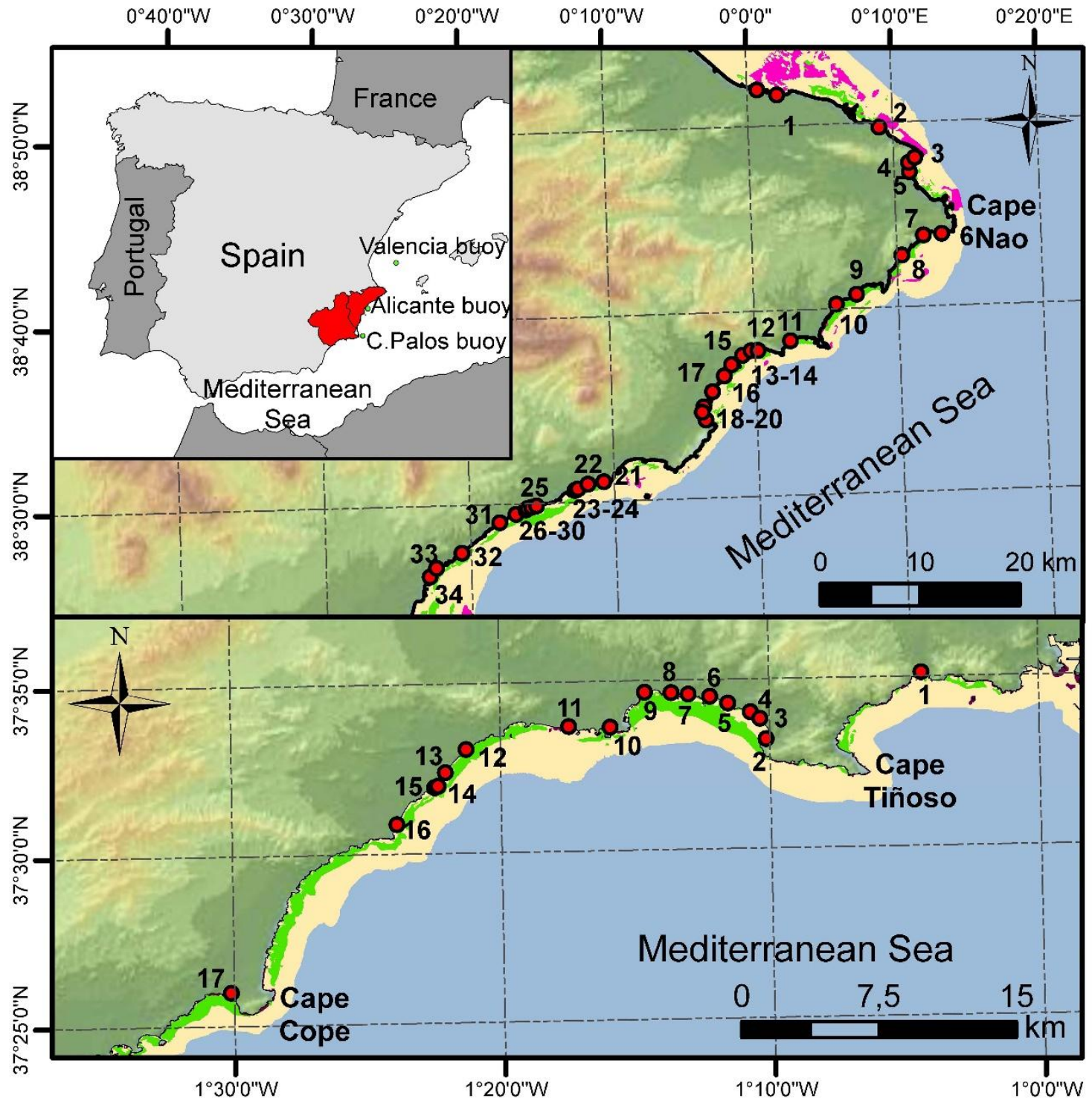

Figure 1. Location of gravel beaches in the study area. (a) Northern part of the province of Alicante. (b) South-west of the province of Murcia.

For the selection of the influential variables in parameters $A$ and $B, 31$ variables were analysed described below. 
Table 1. Analysed variables. The description and meaning of each variable can be seen in supplementary material 1.

\begin{tabular}{|c|c|}
\hline Variable & Variable \\
\hline Modality (unimodal or bimodal sample) & Profile starting slope $\left(\mathrm{m}_{\mathrm{i}}\right)$, between MWL and $-2 \mathrm{~m}$ \\
\hline $\mathrm{D}_{10}$ & Iribarren number (CP) \\
\hline$D_{50}$ & Surf similarity index (CP) \\
\hline $\mathrm{D}_{90}$ & Beach width $\left(A_{p}\right)$ \\
\hline Wave height in deep water; $\mathrm{H}_{\mathrm{o}}(\mathrm{MF})$ & Meadow offshore depth $\left(y_{\text {ip }}\right)$ \\
\hline Period; $T_{p}(M F)$ & Meadow onshore depth $\left(\mathrm{y}_{\mathrm{fp}}\right)$ \\
\hline Probability of occurrence (f MF) & Meadow medium depth $\left(\mathrm{y}_{\mathrm{mp}}\right)$ \\
\hline Deepwater steepness; $\mathrm{H}_{\mathrm{o}} / \mathrm{L}_{\mathrm{o}}$ (MF) & Meadow width $\left(A_{p P o}\right)$ \\
\hline Wave height in deep water; $\mathrm{H}_{\mathrm{o}}(\mathrm{ME})$ & Meadow slope $\left(\mathrm{m}_{\mathrm{p}}\right)$ \\
\hline Period; $\mathrm{T}_{\mathrm{p}}(\mathrm{ME})$ & Plant density (D) \\
\hline Probability of occurrence ( $\mathrm{f} M E$ ) & Stem height $\left(A_{t}\right)$ \\
\hline Deepwater steepness; $H_{o} / L_{o}(M E)$ & $\mathrm{K}_{\mathrm{v} \_}$Méndez \\
\hline Wave height in deep water; $\mathrm{H}_{\mathrm{o}}(\mathrm{CP})$ & $\mathrm{K}_{\mathrm{v} \_}$Cavallaro \\
\hline Period; $T_{p}(C P)$ & $\mathrm{K}_{\mathrm{v} \_}$Koftis\&Prinos \\
\hline Probability of occurrence; ( $\mathrm{fCP}$ ) & $\mathrm{K}_{\mathrm{v} \_}$Maza \\
\hline Deepwater steepness; $\mathrm{H}_{\mathrm{o}} / \mathrm{L}_{\mathrm{o}}(\mathrm{CP})$ & \\
\hline \multicolumn{2}{|c|}{$\begin{array}{l}\text { MF swell most frequent, ME swell most energetic, } \mathrm{CP} \text { swell perpendicular to the coast, and } \mathrm{L}_{\circ} \\
\text { is the deepwater wavelength. }\end{array}$} \\
\hline
\end{tabular}

Sedimentological data (Modality, $D_{10}, D_{50}$ and $D_{90}$ ) were obtained from the analysis and processing of the granulometric tests carried out on the different samples obtained in each of the beaches. The samples were collected by the University of Alicante in 2012 (Alicante) and 2014 (Murcia), at least four samples were taken in each beach so that the obtained information were representative of the entire beach.

The data referring to maritime climate (wave height, period, probability of occurrence and direction) were obtained from the data provided by the directional buoys of the "REDEXT" network and the "REDCOS" network of the Public Organization Puertos del Estado (http://www.puertos.es). The Valencia 2630 buoy $\left(39.52^{\circ} \mathrm{N}-0.21^{\circ} \mathrm{E}\right.$, at a depth of $260 \mathrm{~m}$ - deep water) was used for the study of incident waves on beaches from the northern limit of the province of Alicante to Cape Nao (beaches from 1 to 5 of the province of Alicante). Alicante 1616 buoy $\left(38.25^{\circ} \mathrm{N}-0.41^{\circ} \mathrm{W}\right.$, at $52 \mathrm{~m}$ depth - intermediate waters) with which beaches from Cape Nao to Cape of Huertas (beaches from 6 to 34 of the province of Alicante) were studied. Finally, the Cabo de Palos 2610 buoy $\left(37.65^{\circ} \mathrm{N}-0.33^{\circ} \mathrm{W}\right.$, depth of $230 \mathrm{~m}$ - deep water) was used to study the beaches of the province of Murcia (Figure 1).

For the study of waves on each of the analysed beaches, the AMEVA v1.4.3 program (IHCantabria, 2013), was used. AMEVA is a software that is formed by a set of functions developed in Matlab that integrates the different statistical analysis methodologies, with the purpose of studying and characterizing environmental variables. From this software we obtained: wave height $\mathrm{H}_{s, 12}$ (wave height exceeded only 12 hours per year) as well as the associated period $(T)$ and probability of occurrence of each wave direction $(f)$ for each of the incident directions in each of the beaches. In order to work with all the data in deep water, a reverse propagation was applied to the data corresponding to the Alicante 1616 buoy 
(because it is the only buoy found in relatively shallow waters), using the corresponding factors of shoaling and refraction.

Finally, for each of the beaches, the wave height perpendicular to the beach (PC), the wave height with the highest frequency (MF) and the wave height with the highest energy (ME; higher wave height), as well as all the elements associated with them (period, frequency, direction, etc.) were selected.

The characteristics of the Posidonia oceanica meadow were obtained from the Ecolevante (2006) and EcoMAG (2009) datasheets, obtaining plant density, stem height, leaf length, mean depth, onshore depth, offshore depth, width and slope of the meadow. From these data, the energy reduction coefficient $K_{v}$ was obtained following the formulation proposed by Mendez and Losada (2004) and the values of the parameters $\alpha, \beta$ and $\gamma$ (dependent on the flexibility characteristics of the plants) proposed by Méndez et al. (1999), Cavallaro et al. (2011), Koftis and Prinos (2012) and Maza et al. (2013) (Table 2).

Table 2. Parameters $\alpha, \beta$ and $\gamma$ to calculate $K_{v}$.

\begin{tabular}{lcccc}
\hline Studies & $\boldsymbol{\alpha}$ & $\boldsymbol{\beta}$ & $\mathbf{Y}$ & Range $\mathbf{R}_{\mathbf{e}}$ \\
\hline Méndez et al. (1999) & 0.4 & 4,600 & 2.9 & $2,300-20,000$ \\
Cavallaro et al. (2011) & 0 & 2,100 & 1.7 & $200-15,500$ \\
Koftis and Prinos (2012) & 0.1 & 2,100 & 1 & $1,000-3,200$ \\
Maza et al. (2013) & 1.61 & 4,600 & 1.9 & $2,000-7,000$ \\
\hline
\end{tabular}

Finally, before generating models for parameters $A$ and $B$, a selection of the variables to be used in the finite elements numerical models was made. To this end, firstly, the analysis of bivariate correlations was carried out using the SPSS v.20 computational program (IBM, 2011), studying the relationship of each variable with parameters $A$ and $B$, with the objective of reducing the influential variables in both parameters as much as possible. It should be noted that this analysis only shows linear correlations, therefore a low value does not mean that there is no relationship between the variable and the study parameter.

\subsection{Modelling}

Once the most influential variables in both parameters were determined, linear functions and mathematical models were obtained for the calculation of $A$ and $B$ from these variables. For this purpose, $90 \%$ of the data ( 46 beaches) were used to generate the models and $10 \%$ ( 5 beaches) were used for validation. Data for validation were randomly selected not to condition the results. Finally, the results obtained by the generated models were compared with those of the Van der Meer (1988) and Powell (1990).

\subsubsection{Multiple linear regression model}

The simple linear regression model is not suitable for modelling Parameters A and B of the power function of the equilibrium profile, since explaining both generally requires more than one factor to be considered. It is then necessary to use multiple linear regression models. 
In the multiple linear regression model, the independent variable (that may be the endogenous variable or a transformation of endogenous variables), is a linear function of $k$ variables corresponding to the explanatory variables (or transformations thereof) and a random disturbance or error. The model also includes a separate term. If we designate with $y$ to the dependent factor, by $x_{2}, x_{3}, \ldots, x_{k}$ to the independent variables and by $u$ to the random error or disturbance, the multiple linear regression model will be given by Equation 9. Linear models can also be represented by polynomial functions (Equation 10) or exponential functions (Equation 11), where the parameters $\alpha_{i}$ and $\beta_{i}$ are fixed and unknown. A linear model can be generated from variables that are polynomial or exponential functions of other variables. This method of linearization has been defined and applied in the methodologies published in (Cortés et al., 2000; Villacampa et al., 1999a; Villacampa et al., 1999b) using mathematical functions, including polynomials and exponential and compositions of mathematical functions. Specifically, generically, Cortés et al. (2000) works with a set of variables and their transformations, resulting from the application of mathematical functions to the variables, to obtain models of linear regression in the new variables. Therefore, the final independent variables used to predict a dependent one are transformed functions of varying degrees of the original variables.

$$
\begin{gathered}
y=\beta_{1}+\beta_{2} x_{2}+\beta_{3} x_{3}+\cdots+\beta_{k} x_{k}+u \\
y=\beta_{1}+\beta_{2} x_{2}+\beta_{3} x_{3}^{2}+\cdots+\beta_{k} x_{k}{ }^{k-1}+u \\
y=\beta_{1}+\beta_{2} e^{\alpha_{2} x_{2}}+\beta_{3} e^{\alpha_{3} x_{3}}+\cdots+\beta_{k} e^{\alpha_{k} x_{k}}+u
\end{gathered}
$$

The good fit of the generated linear models was verified by the Pearson's coefficient $R^{2}$ (Equation 12) and the adjusted Pearson's coefficient $\overline{R^{2}}$ (Equation 13). The main feature of the adjusted $\overline{R^{2}}$ is that it imposes a penalty when adding new variables to a model.

$$
\begin{gathered}
\mathrm{R}^{2}=1-\frac{\mathrm{RSS}}{\mathrm{TSS}} \\
\overline{\mathrm{R}^{2}}=1-\frac{\mathrm{RSS} /(\mathrm{n}-\mathrm{k}-1)}{\mathrm{TSS} /(\mathrm{n}-1)}
\end{gathered}
$$

where RSS is the regression sum of squares, TSS is the total sum of squares, $n$ is the sample size and $k$ reflects the number of variables.

Thus, through the linear regression function of the SPSS v.20 computational program (IBM, 2011), various models for parameters $A$ and $B$ were generated. This program allows us to enter all the desired variables, and by the backward method generates different models eliminating variables successively until reaching the minimum error. Using this method, linear models for parameter A and B were generated using all data (except for the 10\% that were used for validation). In addition, models were generated for each type of beach (Table 3 ) proposed by Aragonés et al. (2015).

Table 3. Type of gravel beaches according to Aragonés et al. (2015).

\begin{tabular}{c|l}
\hline Type & \multicolumn{1}{c}{ Characteristics } \\
\hline Type 1: Sand and Gravel & The material is mixed along the entire beach, but the
\end{tabular}




\begin{tabular}{l|l}
\hline & $\begin{array}{l}\text { proportion of sand is much greater than the } \\
\text { proportion of gravel. They are usually bimodal } \\
\text { beaches whose material comes from both rivers and } \\
\text { ravines } \\
\text { A clear separation exists between the gravel area and } \\
\text { the sand area, which lies in the swash zone, and the } \\
\text { sand proportion is far greater than that the gravel } \\
\text { proportion. These beaches are also usually bimodal } \\
\text { The materials are mixed at the beach, but the gravel } \\
\text { ratio is much higher. These beaches are the only ones } \\
\text { that are unimodal, and their materials come from } \\
\text { ravines } \\
\text { Is distinguished by a clear separation between the two } \\
\text { materials, with the fraction of gravel being in the area } \\
\text { of the seashore and the sand fraction in the interior } \\
\text { region. These beaches are strongly bimodal } \\
\text { These beaches are generally bimodal, differentiating } \\
\text { themselves by the absence of sand. }\end{array}$ \\
\hline
\end{tabular}

Although the model adjustment results are relatively good, the test results are not satisfactory (supplementary material 2), so in order to try to obtain a better predictive model, as well as to try to reduce the errors made by the equations obtained with the linear models, it was decided to use non-linear models.

\subsubsection{Finite element numerical model}

In the study and modelling of some systems, it is necessary to analyse and determine the relationship between different variables, of which only experimental data are known. There are different methodologies in the literature to obtain the relationship between variables from experimental data. Therefore, models can be defined analytically (mathematical equations) or numerically. Numerically defined models are defined by their value in a finite number of points, from which the value can be obtained at any point.

From the set of selected variables that influence parameters $A$ and $B$, numerical mathematical models were generated using the numerical methodology developed by Navarro-González and Villacampa (2012) and Navarro-González and Villacampa (2016). This methodology generates $\mathrm{n}$-dimensional representation models, and is based on the definition and generation of a geometric model of finite elements (Villacampa et al., 2009).

In both methodologies, the experimental data are normalized to the $\mathrm{n}$-dimensional hypercube, given by $\Omega=[0,1]^{n}$. Each interval $[0,1]$ is divided into $c$ subintervals ( $c$ is called the complexity of the model). A set of $c^{n}$ elements and $(c+1)^{n}$ nodes is generated, where the relationship between the independent variables and the dependent variable(s) is calculated. For example, if we consider a 3-dimensional geometric model with a complexity $c=4$, the total 
function. The minimized error depends on the methodology used. Thus, in Navarro-González and Villacampa $(2012,2013)$ the sum of the squared error (Equation 14) of the values obtained by the interpolation function at each point $\left(z_{j}\right)$ and the initial conditions $\left(P_{j}\right)$ is minimized. While in the methodology based on the Galerkin method (Navarro-González and Villacampa, 2016), the error ( $e(x)$-the difference between the solution and its approximation) is minimized by zeroing the integral defined in Equation 15, where NP is the number of variables in the model, $\vec{N}\left(P_{j}\right)$ is the interpolation function used to determine the value of the model at any point and $W_{j}(x)$ is the selected weight function (collocation method, sub-domain method, Least Square Method, Galerkin method, method of moments). In order to select the complexity, the generation and validation data of the model are used. Thus, the lower complexity that offers better results is selected, in order not to over fit the model.

Error $=\sum_{j=1}^{N P}\left(\vec{N}\left(P_{j}\right) \vec{u}-z_{j}\right)^{2}$

$\int D^{e(x) \cdot W_{j}(x)} d x=0$

Finally, for the evaluation and selection of the best model, the errors made by each of them were analysed. The errors used are absolute error (equation 16) and Mean Absolute Percentage Error (MAPE) (equation 17).

$$
\mathrm{e}=\left|r_{i}-\mathrm{o}_{i}\right|
$$

$$
\text { MAPE }=\frac{1}{\mathrm{n}} \sum_{\mathrm{i}=1}^{\mathrm{n}}\left|\frac{\mathrm{r}_{i}-\mathrm{o}_{i}}{\mathrm{r}_{i}}\right|
$$

Where $r_{i}$ corresponds to the measured values, $o_{i}$ with the values obtained from the network, $n$ is the number of values and $p$ is the number of free parameters of expression.

Once the model was selected, the volume error per linear metre of beach versus the original beach profile was analysed, as well as the area and type of beaches where the largest errors occurred.

\section{RESULTS}

Table 4 shows the results obtained from the correlation study between the different variables and parameters $A$ and $B$, where it is observed that the Iribarren's number $(A=0.716 ; B=-$ $0.389)$, the Surf Similarity Index $(A=0.716 ; B=-0.391)$, the profile starting slope $(A=0.675 ; B$ $=-0.318)$ and the meadow width $(A=0.455 ; B=-0.508)$ are the variables that are most closely related to both parameter $A$ and parameter $B$. However, to select the variables to be used in numerical models, variables were discarded as follows:

First, the sediment variables were discarded for two reasons: i) the correlation obtained with both parameters was relatively low. ii) the variability of the data over a period of one year, since depending on the season and the area of the beach where the sediment sample is taken, these may change from gravel to sand at the same point as indicated by Aragonés et al. (2015). 
Secondly, the wave data perpendicular to the coast were selected, specifically the probability of occurrence $(A=-0.344 ; B=-0.341$ ) and the steepness $(A=0.498 ; B=-0.298)$, since they presented a greater correlation with parameters $A$ and $B$ than the rest of the studied waves. Although Iribarren's number and the Surf Similarity Index are the variables that show the greatest correlation with parameters $A$ and $B$, it was decided to discard them since these are a combination of other variables (steepness and slope). Therefore, slope and wave steepness were used as input independent variables in the models to not condition their combination.

Finally, with regard to the variables related to Posidonia oceanica meadows, the two variables with the greatest correlation with both parameters of study ( $A$ and $B$ ) were selected, these variables are the meadow width $(A=-0.455 ; B=-0.508)$ and the energy reduction coefficient $\mathrm{K}_{\mathrm{v} \_} \operatorname{Maza}(\mathrm{A}=0.412 ; \mathrm{B}=-0.402)$.

For all the above reasons, it was decided to use combinations of the following variables for the generation of the numerical models: the steepness and the probability of occurrence of waves perpendicular to the coast, the profile starting slope, the meadow width, and the $\mathrm{K}_{\mathrm{v}} \mathrm{Maza}$ coefficient. In addition, given the relationship observed by López et al. (2016) between the study parameters ( $A$ and $B$ ) and the beach type, models were also tested with and without this variable.

Table 4. Correlations between the analysed variables and parameters $A$ and $B$.

\begin{tabular}{lcc|lcc}
\hline \multicolumn{1}{c}{ Variable } & Parameter A & Parameter B & \multicolumn{1}{c}{ Variable } & Parameter A & Parameter B \\
\hline Modality & -0.325 & 0.246 & Profile starting slope & 0.675 & -0.318 \\
$\mathrm{D}_{10}$ & 0.139 & -0.223 & Iribarren number (CP) & 0.716 & -0.389 \\
$\mathrm{D}_{50}$ & 0.191 & -0.286 & Surf Similarity Index (CP) & 0.716 & -0.391 \\
$\mathrm{D}_{90}$ & 0.081 & -0.106 & Beach width & 0.108 & -0.207 \\
$\mathrm{H}_{\mathrm{o}}(\mathrm{MF})$ & 0.068 & 0.031 & Meadow onshore depth & 0.258 & -0.118 \\
$\mathrm{~T}_{\mathrm{p}}(\mathrm{MF})$ & 0.126 & -0.104 & Meadow offshore depth & 0.003 & -0.027 \\
$\mathrm{f} \mathrm{MF}$ & 0.063 & 0.072 & Meadow medium depth & 0.043 & -0.053 \\
$\mathrm{H}_{\mathrm{o}} / \mathrm{L}_{\mathrm{o}}(\mathrm{MF})$ & 0.120 & -0.102 & Meadow width & 0.455 & -0.508 \\
$\mathrm{H}_{\mathrm{o}}(\mathrm{ME})$ & -0.032 & 0.088 & Meadow slope & -0.265 & 0.289 \\
$\mathrm{~T}_{\mathrm{p}}(\mathrm{ME})$ & 0.183 & -0.033 & Plant density & 0.390 & -0.317 \\
$\mathrm{f} \mathrm{ME}$ & -0.121 & 0.055 & Stem height & 0.077 & 0.123 \\
$\mathrm{H}_{\mathrm{o}} / \mathrm{L}_{\mathrm{o}}(\mathrm{ME})$ & 0.182 & -0.029 & $\mathrm{~K}_{\mathrm{v}}$ Méndez & -0.393 & 0.202 \\
$\mathrm{H}_{\mathrm{o}}(\mathrm{CP})$ & -0.310 & 0.063 & $\mathrm{~K}_{\mathrm{v}}$ Cavallaro & -0.410 & 0.394 \\
$\mathrm{~T}_{\mathrm{p}}(\mathrm{CP})$ & 0.256 & -0.152 & $\mathrm{~K}_{\mathrm{v}}$ Koftis\&Prinos & -0.362 & 0.223 \\
$\mathrm{f} \mathrm{CP}$ & -0.344 & 0.341 & $\mathrm{~K}_{\mathrm{v}}$ Maza & -0.412 & 0.402 \\
$\mathrm{H}_{\mathrm{o}} / \mathrm{L}_{\mathrm{o}}(\mathrm{CP})$ & 0.498 & -0.298 & & &
\end{tabular}

The correlation is significant at level 0.05 (bilateral).

The backward method of the multiple regression analysis of the SPSS v.20 computer program (IBM, 2011) was used to generated linear models. This method generates models and progressively eliminates those variables that are less influential, which is why, in this case, all the studied variables except sedimentological data (for the reasons explained above) were introduced in the program. Thus, 3 models for parameter $A$ and 2 for parameter $B$ were obtained without distinguishing between beach types, with $R^{2}$ values of approximately 0.66 and 0.49 , respectively (Figure $2 \mathrm{a}, \mathrm{b}$ ). When linear models were generated for each beach type, a single model was obtained for each type with an almost perfect fit (Figure 2 a,b). However, 
when these models were used to predict the parameter A or B in other beaches (Figure $2 \mathrm{c}, \mathrm{d}$ ) large errors result, being larger for models with higher fit during calibration (absolute error for parameter $A$ is 0.036 for the model without beach type variable vs. 0.264 for the beach type models; for parameter $B$ the absolute error is 0.133 vs. 0.808 , respectively). This indicates that these models have an over-adjustment, and therefore, do not allow us to predict the studied parameters for beaches with different characteristics than those used to generate the model. The characteristics and the coefficients of the generated models can be seen in supplementary material 2.
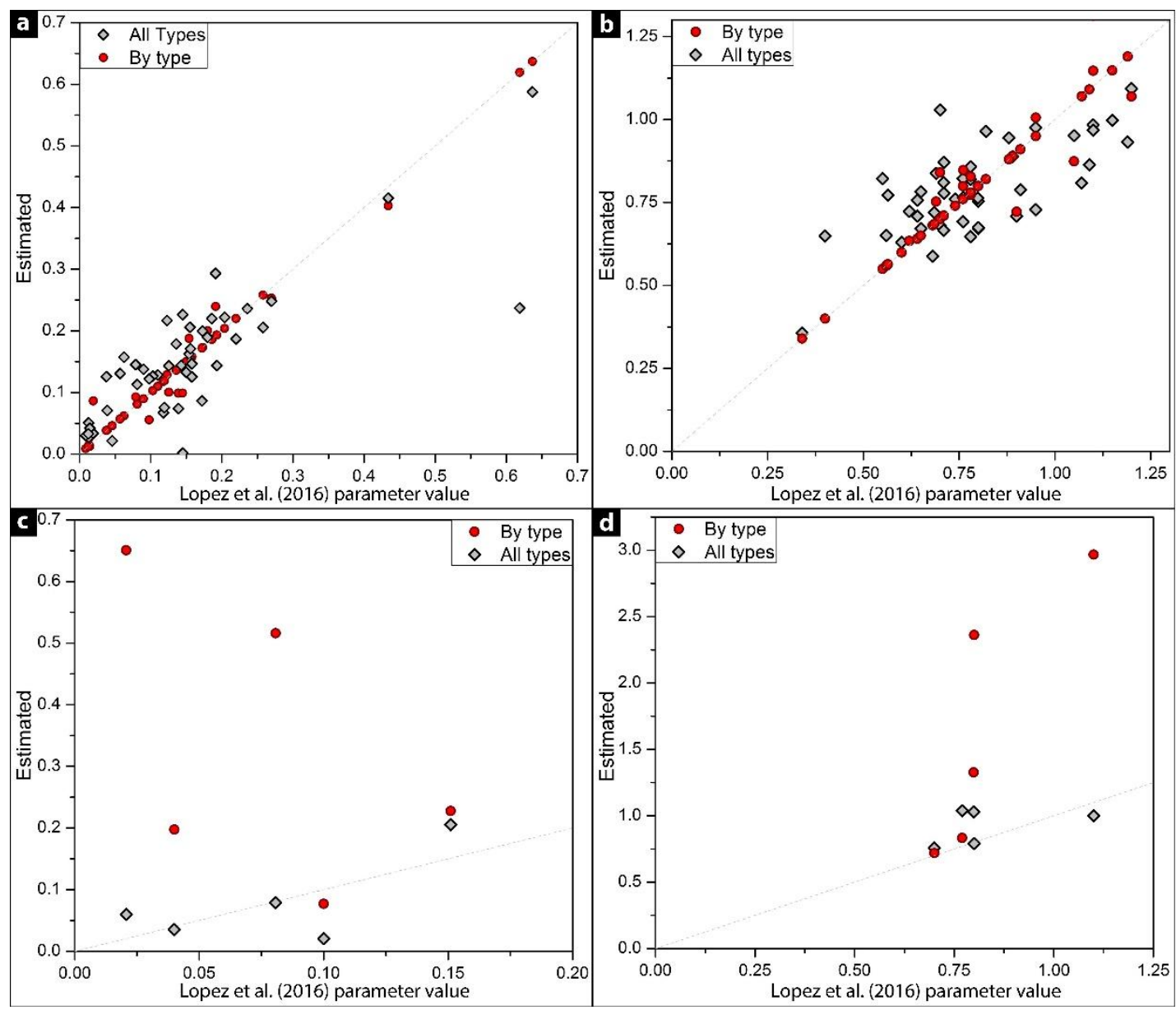

Figure 2. Linear models. a) Estimated parameter A during calibration. b) Estimated parameter B during calibration. c) Estimated parameter A during test. d) Estimated parameter B during test.

Regarding the finite element numerical models, three models were generated using different inputs and complexities (5, 10, 15 and 20). The models and the variables are: 1) Type of beach, probability of occurrence of the wave perpendicular to the coast ( $\mathrm{fP}$ ), the steepness of the wave perpendicular to the coast $\left(\mathrm{H}_{0} / \mathrm{L}_{0} \mathrm{CP}\right)$, slope and $\mathrm{K}_{\mathrm{v}_{-}}$Maza coefficient. 2) Type of beach, probability of occurrence of the wave perpendicular to the coast ( $\mathrm{fP}$ ), the steepness of the wave perpendicular to the coast $\left(\mathrm{H}_{\mathrm{o}} / \mathrm{L}_{\mathrm{o}} \mathrm{CP}\right)$, slope, Posidonia meadow width and $\mathrm{K}_{\mathrm{v}_{-}}$Maza coefficient. 3) Probability of occurrence of the wave perpendicular to the coast ( $\mathrm{CP}$ ), the steepness of the wave perpendicular to the coast $\left(\mathrm{H}_{0} / \mathrm{L}_{0} \mathrm{CP}\right)$, slope, Posidonia meadow width and $K_{v_{2}}$ Maza coefficient. As can be seen in Figure 3, for both parameter $A$ and $B$, the errors decrease as the complexity increases, and when the beach type variable or meadow width are 
complexities 15 and 20, with little difference between the two. For parameter A, the smallest errors occur for Model_2 with a MAPE of 13.9\% and 8.0\%, and an absolute error of 0.015 and 0.010 , respectively. For parameter B, the best model is also Model_2, with a MAPE of $4.1 \%$ and $3.1 \%$, and an absolute error of 0.029 and 0.023 , respectively.
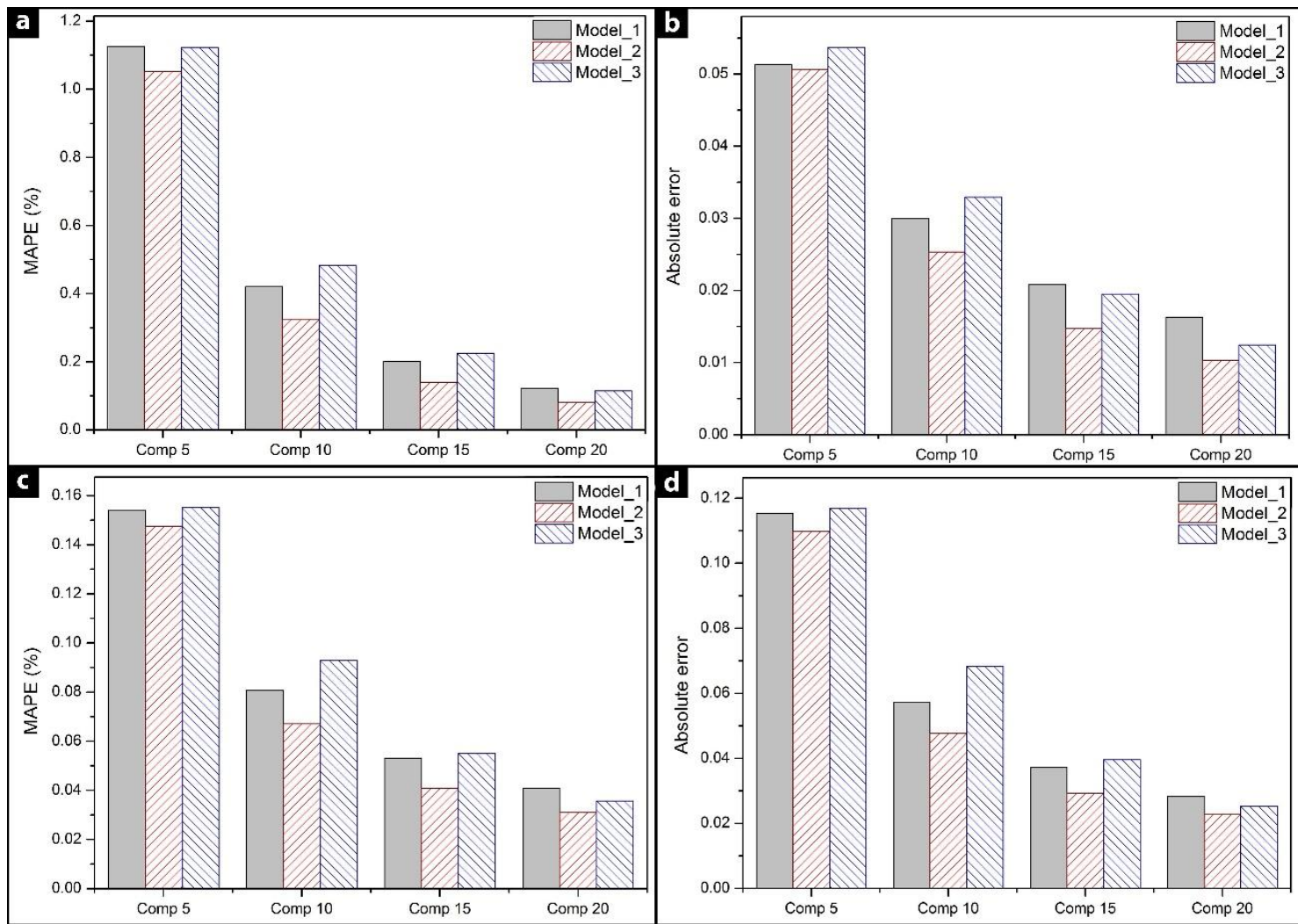

Figure 3. Errors resulting during finite element numerical model calibration. $\mathbf{a}$ and $\mathbf{b})$ Parameter A. $\mathbf{c}$ and

d) Parameter B.

On the other hand, if the results obtained for test are analysed, it can be seen that errors are similar to those committed during model calibration (Figure 4). However, it is noted that the model that does not include the beach type variable (Model_3) generated fewer error than the other two for parameter A. For parameter B the best fir is obtained by Model_1 (without meadow width variable). Therefore, it is complex to select one model due to the different results between calibration and test. Thus, first, we select complexity, remaining with a complexity of 15 , since the difference between 15 and 20 is minimal and a lower complexity implies a shorter computation time. Secondly, in order to select the more suitable model, it is decided to obtain the volume error from each one or a combination of them. 

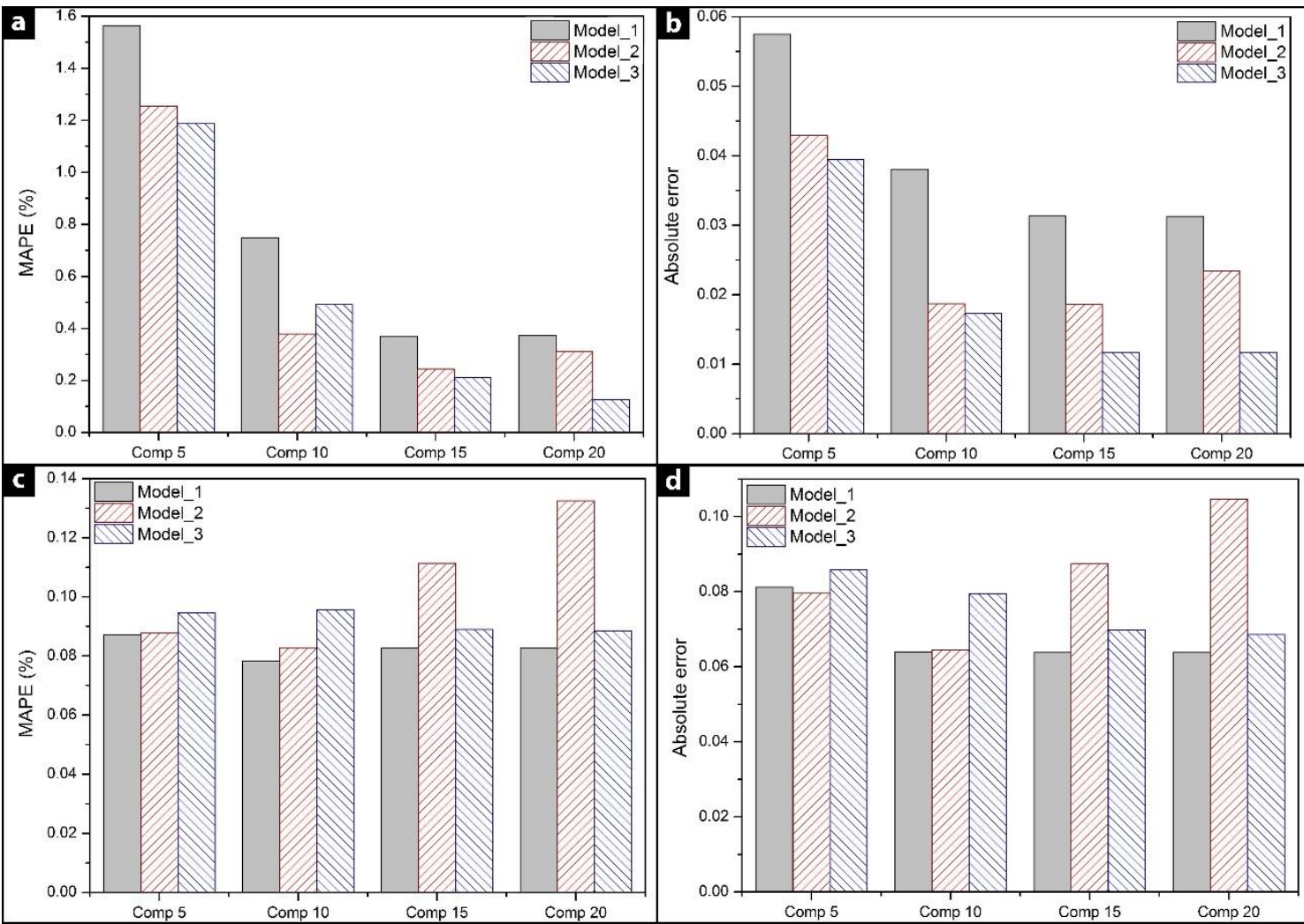

Figure 4. Errors committed during finite element numerical model test. $\mathbf{a}$ and b) Parameter A. $\mathbf{c}$ and d)

Parameter B.

Figure 5a shows the volume error during calibration and test after the combination of different $A$ and $B$ numerical models. Both on calibration and testing, the errors of the different models are very similar. For calibration, the combination of Model_3 for A and Model_3 for B is the one that makes the greatest error, with an increase of $34.8 \%$ with respect to the best model obtained from the combination of Model_2 for parameter A and Model_1 for parameter B. With regard to the test, again it is the combination of Model_2 (parameter A) and Model_1 (parameter $B$ ) that produces the minimum error, while the rest of models imply an increase of 26-30\%. Therefore, Model_2 for parameter A and Model_1 for parameter B as the optimal models were selected.

Once the model was chosen, the errors were analysed for each type of beach (Figure $5 b$ and $5 c$ ), and it was observed that the greatest absolute error occurs in type 1 and type 2 beaches, being 1.8 times higher than the one related to the rest of the other beaches types $(0.015-$ 0.020). However, when analysing the MAPE it is observed that type 4 beaches are characterized by the largest errors (39.2\%), followed very closely by type 1 beaches (13.9\%), 

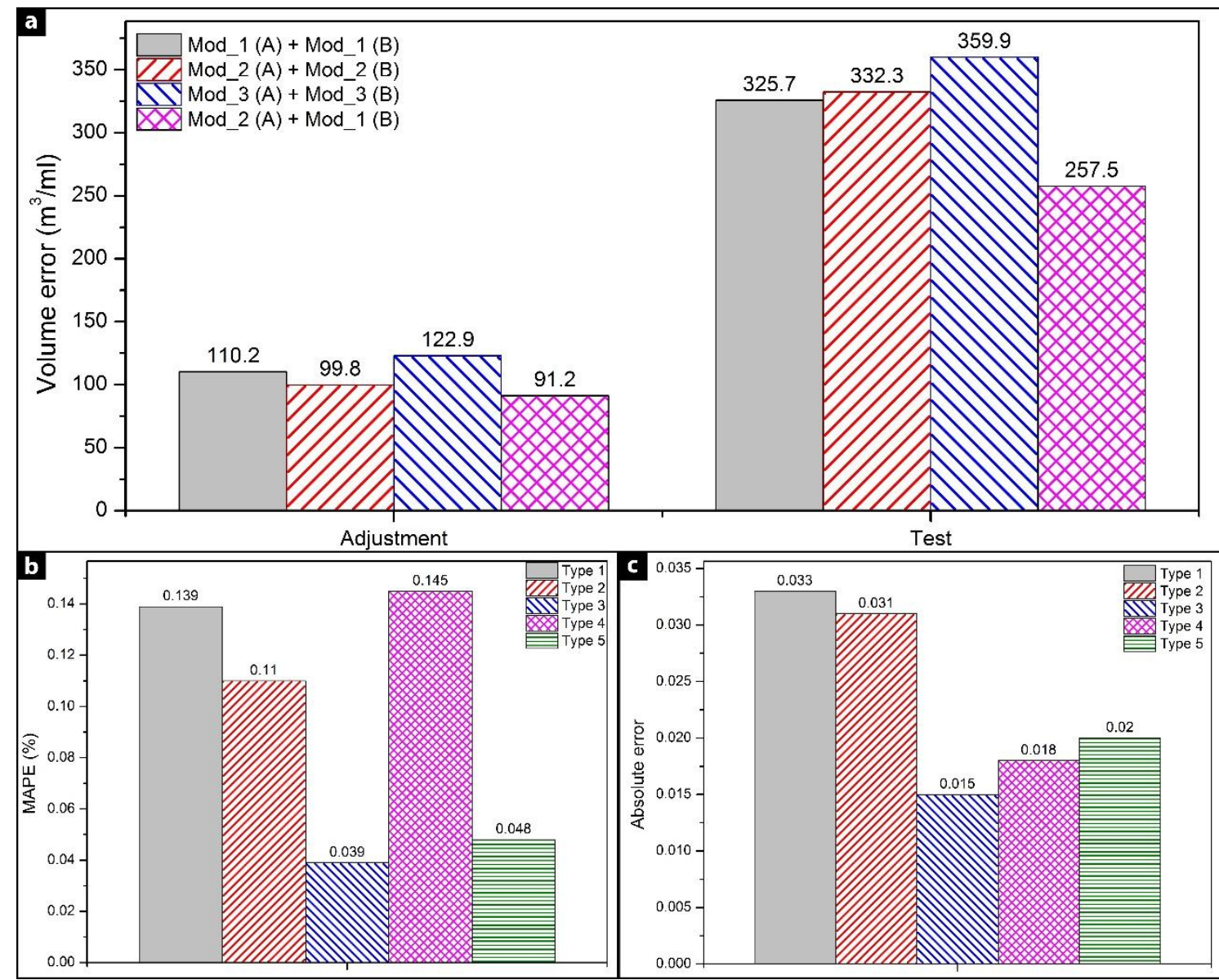

Figure 5. a) Volume error per $\mathrm{ml}$ beach for calibration and test. b) MAPE and (c) Absolute error by type of beach according to Aragonés et al. (2015) for the selected numerical model.

As for the distribution of the error along the profile, as shown in Figure 6, the greatest error occurs in the deepest part of the profile. The profile obtained from the modelled parameters generally tends to be below the real profile and the López et al. (2016) EBP (Equilibrium beach profile), with an average value of $0.28 \mathrm{~m}$ (Figure $6 \mathrm{c}$ ), with a maximum value of $0.97 \mathrm{~m}$ on the 


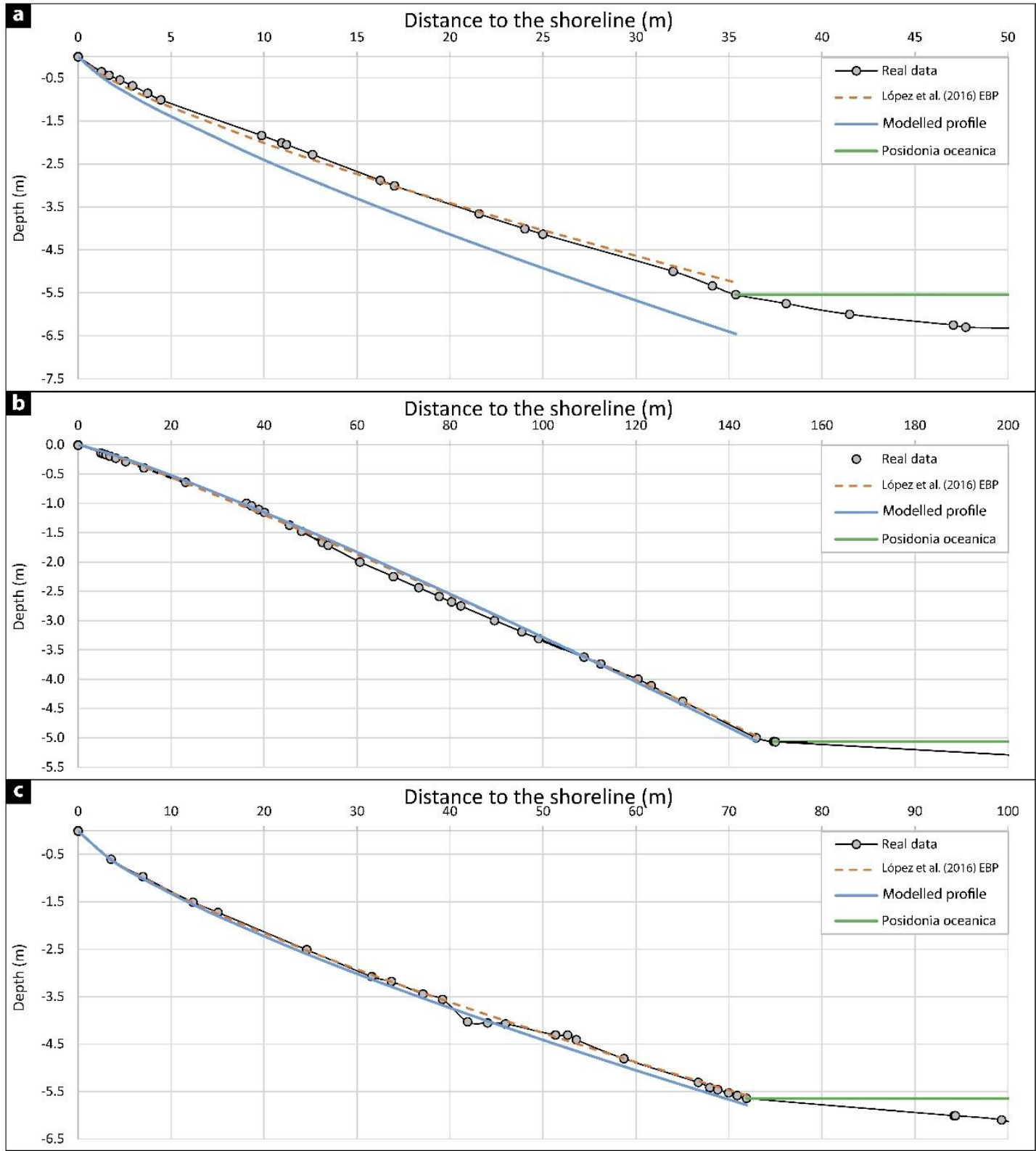

Figure 6. Comparison of real, López et al. (2016) EBP and modelled profiles. a) Los Tiestos beach. b) Covaticas beach. c) Llobella beach.

Finally, the results of the model were compared with the results obtained by applying Van der Meer and Powell formulations. In Figure $7 \mathrm{a}$ and $7 \mathrm{~b}$, it can be seen how the values of parameters $A$ and $B$ obtained by both formulations are very different from those values set in each of the beaches by López et al. (2016). This difference has an average absolute error for parameter A of 2.003 for Van der Meer (1988) and 0.288 for Powell (1990), and 0.157 and 0.168 for parameter $B$, respectively. These errors in obtaining these parameters mean an average error of volume (difference between the real and estimated profile) of $20917 \mathrm{~m}^{3} / \mathrm{ml}$ beach for Van der Meer (1988) and $1417 \mathrm{~m}^{3} / \mathrm{ml}$ beach for Powell (1990). This means an increase of 20810 and $1310 \mathrm{~m}^{3} / \mathrm{ml}$ compared to the selected numerical model (Model_2 for parameter A and Model_1 for parameter B) and 20884 and $1384 \mathrm{~m}^{3} / \mathrm{ml}$ versus the real profile data (Figure 7c). In other words, the volume of gravel required for regeneration using the new method (finite element numerical model) is about 80 - 5 times less than with the current 
methods (Van de Meer (1988) and Powell (1990), respectively), with the resulting economic and material savings.
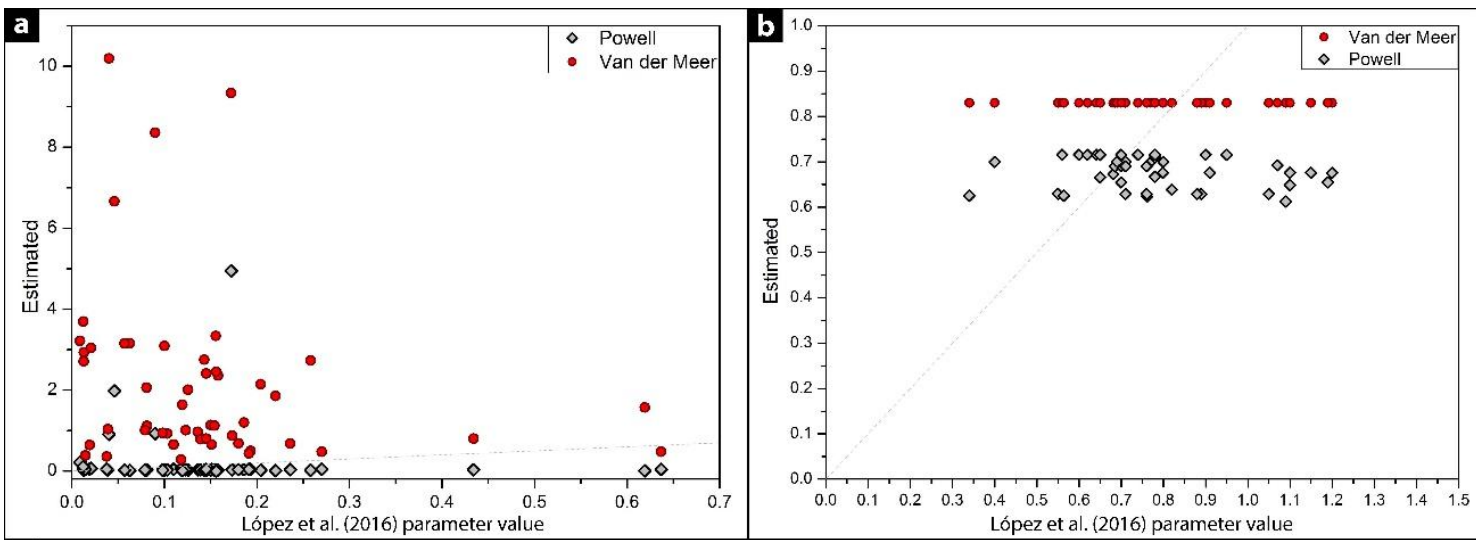

\section{c}

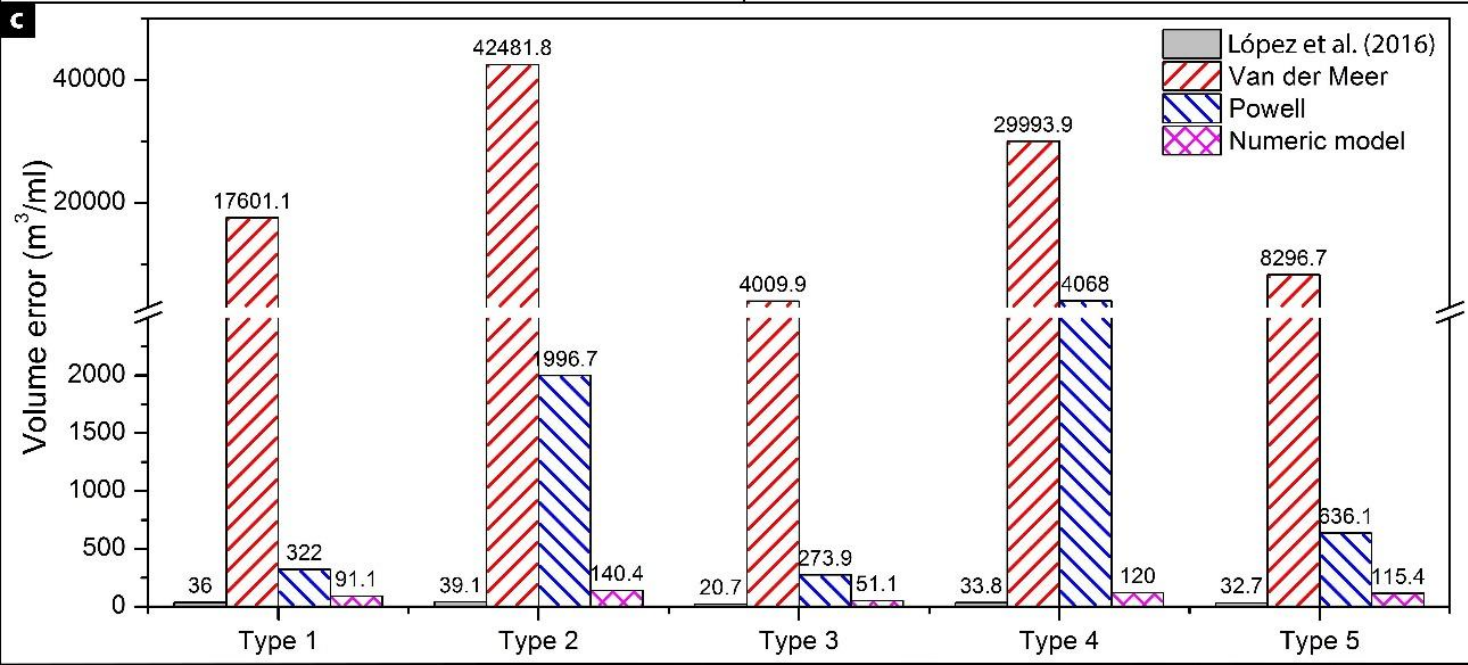

Figure 7. a) Parameter A obtained by Van der Meer (1988) and Powell (1990) versus the parameter proposed by López et al. (2016). b) Parameter B obtained by Van der Meer (1988) and Powell (1990) versus the parameter proposed by López et al. (2016). c) Comparison of volume error for each model.

\section{DISCUSSION}

Due to the increasing use of gravel for beach nourishment all around the world, it is necessary to define accurately the equilibrium beach profile in order to determine the volume of material. At present, for the determination of this profile there are two profiles proposed by Van der Meer (1988) and Powell (1990), which were obtained through channel tests. This is why these formulations present great errors when compared to the real profile of a gravel beach as demonstrated by López et al. (2016), and as has also noted in this study.

The cross-shore profiles used in this study come from bathymetric data taken in a single period of the year. However, these profiles can be considered valid if we take into account that, as Aragonés et al. (2016) studied, the longshore transport of sediments is not relevant in the equilibrium profile, since after comparing the equilibrium profile obtained as the average of 22 years of precision profiles (at least two per year) with the bathymetry profile obtained in a single period, it was observed that the difference was less than $8 \%$. In addition, according to López et al. (2016) the profiles used in this study can be considered as the equilibrium profile 
given that: i) the beach width variation is less than $1 \mathrm{~m} /$ year, i. e. the beaches are stable. ii) From depth $-6 \mathrm{~m}$, the profile between 1987 and 2006 hardly changed $(<30 \mathrm{~cm})$. Therefore, the intermediate zone of the profile must be stable and can be assimilated to the equilibrium profile.

Once it was established that the profiles could be considered as the equilibrium profile, the variables involved in its formation were analysed to determine which the most influential variables were. Thus, in the correlation analysis (Table 4) it was observed that the variables that presented a greater relationship with the parameters that define the equilibrium profile were the combination of slope, wave height and wave period perpendicular to the coast, as well as the energy reduction coefficient proposed by Maza et al. (2013). However, it was decided to use them individually in the models so as not to condition their combination. From this analysis, it is surprising that sediment sizes do not influence the profile. This may be due, as indicated by López et al. (2016), to its great variability throughout the year at the same point, because due to the movement of sediment for the formation of beach berm during storms (Baldock et al., 2005) the size varies depending on the time of year in which the samples are taken. For these two reasons (correlations and sample variability), these variables were not used in the numerical models. Likewise, the possible influence of the type of gravel beach (Aragonés et al., 2015) on the values of the parameters A and B was taken into account, so models were generated with and without the beach type variable.

Once the variables were analysed, linear models were carried out jointly and individually for the different types of beaches (Figure 2). From the results, it is observed that the fit during the calibration of the models is almost perfect, but the validation of the same generates big errors, possibly due to an over-adjustment of the models, which prevents predicting results when using values of the variables different from those used during model calibration. Therefore, it was decided to use numerical models. Figure 4 shows that the numerical models generated are capable of reproducing and qualitatively estimating the cross-shore profile of each type of beach. (Aragonés et al., 2015). When these errors are compared with the errors produced by the formulas currently used, it is observed that there is a great difference. Current formulas present a much larger volume error than the generated models (Figure 7) in the order of 80 and 5 times higher for Van der Meer (1988) and Powell (1990), respectively. This may be due to the fact that these formulas, as mentioned above, were obtained by channel tests at different scales, and therefore do not take into account the possible local effects such as the presence of Posidonia oceanica. For example, the three-dimensional structure of rhizomes form a certain reinforcement for the sandy sediment of the submerged beach which, along with the roots and leaves, hinder the sedimentary movements of the seabed, consolidating the sandy substratum and making the submerged beach profile be more vertical than usual (Medina et al., 2001).

On the other hand, the results were analysed by type of beach, to study the effect of the models depending on whether the beach was made up of a thinner or thicker size, given that the bed shear is due to inertia effects and that it varies linearly with the medium grain size. Interestingly, the results show that the selected A and B models are more accurate on type 3 beaches. Type 1 and 4 beaches are the ones with the biggest errors, either absolute error or MAPE (Figure 5). Validation with beaches within the study area is consistent with the results of 
the models on the other beaches (Figure 4). In addition, when we analyse in detail the adjustment of the equilibrium profile on the real profile, we can observe that the numerical models represent almost perfectly the real profile in the closest part of the coastline, while as we move away from the coast, the obtained profile tends to be deeper than the real one. This may be due to the presence of Posidonia oceanica meadows at the end of the profile, since the Posidonia meadow acts as a reef or rocky slab by modifying the slope of the profile in this area and making it more or even completely flat, a feature that is not possible to represent by the power function (Figure 6). This is why most authors propose profiles composed of several curves (Bernabeu et al., 2003; Powell, 1990; Van der Meer, 1988), which generally range from the mean water level to the step and from the step to the bottom. In the case of the study area, the curves range from the mean water level to the beginning of the Posidonia oceanica meadow, and from the latter to the end of the meadow.

The fact that the modelled profile is deeper than the actual profile implies that in the study of a beach nourishment the volume of material needed for it would be underestimated. However, this error is in the order of $1300 \mathrm{~m}^{3} / \mathrm{ml}$ less than the volume underestimated by other models such as Powell (1990). This in turn implies a lower erosion of the dry beach during the formation/stabilization of the profile, which knowing the model error could be corrected by pouring more material than required according to the model, about $70-80 \mathrm{~m}^{3}$ more material per $\mathrm{ml}$ of beach.

Although the model represents a step forward in modelling the profile of gravel beaches between the mean water level and the step or Posidonia meadow (in our case), the model can still be improved, especially in profile prediction. For this purpose, important factors that are not explained by the model and that can improve the model's behaviour must be taken into account. Some of these factors are: i) turbulence of percolation depending on the beach typology; ii) vertical velocity under breaking waves (Pedrozo-Acuña et al., 2008), and iii) the ground consolidation by Posidonia oceanica (Medina et al., 2001).

\section{CONCLUSIONS}

The results obtained show that the finite element numerical models generated can accurately predict both parameter $A$ and parameter $B$, for the modelling of the cross-shore gravel beaches profile (from MWL to Posidonia oceanica meadow) according to the Aragonés et al. (2015) classification. The results show that the combination of both models (parameter A and B) is more accurate in predicting type 3 beaches while in type 1 and 4 beaches the worst fits are obtained. The validation carried out with $10 \%$ of the beaches considered within the study area shows that the model is valid both for the chosen system and for those international areas with similar characteristics to those studied here. However, once the cross-shore profile has been analysed, it can be seen that it is in the final part of the same where the greatest errors are observed, predicting a slightly deeper profile than the real profile. This is possibly due to the stabilization effect of Posidonia oceanica roots against sediment erosion. Nevertheless, due to the results obtained, it can be concluded that coastal engineers for the construction of this type of beaches can use the proposed models. Considering that knowing the model error, more material will have to be poured than calculated one, in order to avoid the loss of beach width due to the formation of the profile after nourishment. Furthermore, it 
will allow us to ensure the well-being of the marine flora near the area of actuation. Since, if we define the profile with a formula or model that gives us a more vertical profile than the equilibrium profile, this profile during its formation will tend to the equilibrium profile and therefore it will be more flat. This could cause the grounding of vegetation and its subsequent death, causing a total destabilization of the profile and ecosystem of the area of action.

2

\section{REFERENCES}

Aagaard, T. and Hughes, M.G., 2006. Sediment suspension and turbulence in the swash zone of dissipative beaches. Marine Geology, 228(1), 117-135.

Aminti, P.; Cipriani, L.E., and Pranzini, E., 2003. Back to the beach': converting seawalls into gravel beaches. Coastal Systems and Continental Margins, 7, 261-274.

Aragonés, L.; López, I.; Villacampa, Y.; Serra, J.C., and Saval, J.M., 2015. New Methodology for the Classification of Gravel Beaches: Adjusted on Alicante (Spain). Journal of Coastal Research, 31(4), 1023-1034.

Aragonés, L.; Serra, J.C.; Villacampa, Y.; Saval, J.M., and Tinoco, H., 2016. New methodology for describing the equilibrium beach profile applied to the Valencia's beaches. Geomorphology, 259, 1-11.

Austin, M.J., 2005. Swash, groundwater and sediment transport processes on a gravel beach. Loughborough University, Master's thesis, p.

Baldock, T.E. and Holmes, P., 1997. Swash hydrodynamics on a steep beach. Proceedings of the Coastal Dynamics' 97, pp. 784-793.

Baldock, T.E.; Hughes, M.G.; Day, K., and Louys, J., 2005. Swash overtopping and sediment overwash on a truncated beach. Coastal Engineering, 52(7), 633-645.

Benetazzo, A.; Fedele, F.; Carniel, S.; Ricchi, A.; Bucchignani, E., and Sclavo, M., 2012. Wave climate of the Adriatic Sea: a future scenario simulation. Natural Hazards and Earth System Sciences, 12(6), 2065-2076.

Bernabeu, A.M.; Medina, R., and Vidal, C., 2003. Wave reflection on natural beaches: an equilibrium beach profile model. Estuarine, Coastal and Shelf Science, 57(4), 577-585.

Bodge, K.R., 1992. Representing equilibrium beach profiles with an exponential expression. Journal of Coastal Research, 8(1), 47-55.

Bonaldo, D.; Benetazzo, A.; Sclavo, M., and Carniel, S., 2015. Modelling wave-driven sediment transport in a changing climate: a case study for northern Adriatic Sea (Italy). Regional Environmental Change, 15(1), 45-55.

Boon, J.D. and Green, M.O., 1988. Caribbean beachface slopes and beach equilibrium profiles. Proceedings of the 21st Conference on Coastal Engineering (Torremolinos, Spain), pp. 16181630.

Carter, R.W.G. and Orford, J.D., 1993. The morphodynamics of coarse clastic beaches and barriers: A short- and long-term perspective. Journal of Coastal Research, (Special issue 15), 158-179.

Cavallaro, L.; Lo Re, C.; Paratore, G.; Viviano, A., and Foti, E., 2011. Response of Posidonia oceanica to wave motion in shallow-water - Preliminary experimental results. 2011, (32).

Clarke, S.; Dodd, N., and Damgaard, J., 2004. Modeling Flow In and Above a Porous Beach. Journal of waterway, port, coastal, and ocean engineering, 130(5), 223-233.

Cortés, M.; Villacampa, Y.; Mateu, J., and Usó, J.L., 2000. A new methodology for modelling highly structured systems. Environmental modelling \& software, 15(5), 461-470.

Dean, R.G. 1977. Equilibrium Beach Profiles: U.S. Atlantic and Gulf Coasts. Department of Civil Engineering. Ocean Engineering Technical Report. Newark, Delaware.: University of Delaware.

Ecolevante 2006. Estudio ecocartográfico del litoral de las provincias de Alicante y Valencia, Dirección General de Costas, Ministerio de Medio Ambiente, Spain, [Available online: http://www.mapama.gob.es/es/costas/temas/proteccioncosta/ecocartografias/ecocartografia-alicante.aspx].

Ecomag 2009. Estudio ecocartográfico de las provincias de Granada, Almería y Murcia., Dirección General de Costas, Ministerio de Medio Ambiente, Spain [Available online: 
http://www.mapama.gob.es/es/costas/temas/proteccioncosta/ecocartografias/ecocartografia-murcia.aspx].

Fredsoe, J.; Andersen, O.H., and Silberg, S., 1985. Distribution of suspended sediment in large waves. Journal of Waterway, Port, Coastal, and Ocean Engineering, 111(6), 1041-1059.

Ibm 2011. IBM SPSS Statistics for Windows. Version 20.0. ed. Armonk, NY.

Ihcantabria 2013. Análisis Matemático y Estadístico de Variables Medioambientales (AMEVA). In: CANTABRIA, U.D. (ed.). Cantabria, Spain. Available online: http://ihameva.ihcantabria.com/.

Jamal, M.H.; Simmonds, D.J., and Magar, V., 2014. Modelling gravel beach dynamics with XBeach. Coastal Engineering, 89(0), 20-29.

Johnson, C.N., 1987. Rubble beaches versus rubble revetments. Proceedings of the Procedding ASCE Conference on Coastal Sediments 1987 (Virginia, USA), pp. 1216-1231.

Koftis, T. and Prinos, P., 2012. Estimation of wave attenuation over Posidonia Oceanica. Mitteilungen des Lehrstuhls und Instituts für Wasserbau und Wasserwirtschaft der Rheinisch-Westfälischen Technischen Hochschule Aachen, 165.

Lopez De San Roman Blanco, B., 2003. Dynamics of gravel and mixed, sand and gravel, beaches. Imperial College London (University of London), Master's thesis, $\mathrm{p}$.

López, I.; Aragonés, L., and Villacampa, Y., 2016. Analysis and modelling of cross-shore profile of gravel beaches in the province of Alicante. Ocean Engineering, 118, 173-186.

Mason, T.; Priestley, D., and Reeve, D.E., 2007. Monitoring near-shore shingle transport under waves using a passive acoustic technique. Journal of the Acoustical Society of America, 122(2), 737746.

Masselink, G. and Li, L., 2001. The role of swash infiltration in determining the beachface gradient: a numerical study. Marine Geology, 176(1-4), 139-156.

Maza, M.; Lara, J.L., and Losada, I.J., 2013. A coupled model of submerged vegetation under oscillatory flow using Navier-Stokes equations. Coastal Engineering, 80(0), 16-34.

Mccall, R.T.; Masselink, G.; Poate, T.G.; Roelvink, J.A., and Almeida, L.P., 2015. Modelling the morphodynamics of gravel beaches during storms with XBeach-G. Coastal Engineering, 103(Supplement C), 52-66.

Medina, J.R.; Tintore, J., and Duarte, C.M., 2001. Praderas de Posidonia oceánica y la regeneración de playas. Revista de Obras Públicas, 3.409, 31-43.

Mendez, F.J. and Losada, I.J., 2004. An empirical model to estimate the propagation of random breaking and nonbreaking waves over vegetation fields. Coastal Engineering, 51(2), 103-118.

Méndez, F.J.; Losada, I.J., and Losada, M.A., 1999. Hydrodynamics induced by wind waves in a vegetation field. Journal of Geophysical Research: Oceans, 104(C8), 18383-18396.

Moore, B., 1982. Beach profile evolution in response to changes in water level and water height.: University of Delaware, Master's thesis, $\mathrm{p}$.

Navarro-González, F.J. and Villacampa, Y., 2012. A new methodology for complex systems using $n-$ dimensional finite elements. Advances in Engineering Software., 48(1), 52-57.

Navarro-González, F.J. and Villacampa, Y., 2016. A finite element numerical algorithm for modelling and data fitting in complex systems. International Journal of Computational Methods and Experimental Measurements, 4(2), 100-113.

Pedrozo-Acuña, A.; Simmonds, D.J.; Otta, A.K., and Chadwick, A.J., 2006. On the cross-shore profile change of gravel beaches. Coastal Engineering, 53(4), 335-347.

Pedrozo-Acuña, A.; Simmonds, D.J., and Reeve, D.E., 2008. Wave-impact characteristics of plunging breakers acting on gravel beaches. Marine Geology, 253(1), 26-35.

Perlin, A. and Kit, E., 1999. Longshore sediment transport on Mediterranean coast of Israel. Journal of Waterway, Port, Coastal, and Ocean Engineering, 125(2), 80-87.

Pilkey, O.H.; Young, R.S.; Riggs, S.R.; Smith, A.W.S.; Wu, H.Y., and Pilkey, W.D., 1993. The concept of shoreface of equilibrium - A critical review. Journal of Coastal Research, 9(1), 255-278.

Poate, T.; Masselink, G.; Davidson, M.; Mccall, R.; Russell, P., and Turner, I., 2013. High frequency in-situ field measurements of morphological response on a fine gravel beach during energetic wave conditions. Marine Geology, 342(0), 1-13.

Powell, K.A., 1990. Predicting short term profile response for shingle beaches. HR Wallingford report SR, 219.

Puleo, J.A.; Beach, R.A.; Holman, R.A., and Allen, J.S., 2000. Swash zone sediment suspension and transport and the importance of bore-generated turbulence. Journal of Geophysical Research: Oceans, 105(C7), 17021-17044. 
Saengsupavanich, C.; Seenprachawong, U.; Gallardo, W.G., and Shivakoti, G.P., 2008. Port-induced erosion prediction and valuation of a local recreational beach. Ecological economics, 67(1), 93103.

Stockberger, M.T. and Wood, W.L., 1990. Application of Equilibrium Beach Concepts to Sandy Great Lake Profiles. Proceedings of the 22 Coastal Engineering Conference pp. 2291-2303.

Turker, U. and Kabdasli, M.S., 2006. The effects of sediment characteristics and wave height on shapeparameter for representing equilibrium beach profiles. Ocean Engineering, 33(2), 281-291.

Van Der Meer, J.W., 1988. Rock slopes and gravel beaches under wave attack.

Van Wellen, E.; Chadwick, A.J., and Mason, T., 2000. A review and assessment of longshore sediment transport equations for coarse-grained beaches. Coastal Engineering, 40(3), 243-275.

Villacampa, Y.; Cortés, M.; Vives, F.; Usó, J.L., and Castro, M.A., 1999a. A new computational algorithm to construct mathematical models. Advances in Ecological Sciences. Ecosystems and Sustainable Development., 323-332.

Villacampa, Y.; Navarro-González, F.J., and Llorens, J., 2009. A geometric model for the generation of models defined in Complex Systems. Ecosystems and Sustainable Development VII, 71-82.

Villacampa, Y.; Usó-Domènech, J.L.; Mateu, J.; Vives, F., and Sastre, P., 1999b. Generative and recognoscitive grammars of ecological models. Ecological Modelling, 117(2), 315-332. 